\title{
Aspects of Sewage Disposal from Tourist Facilities in National Parks and Other Protected Areas
}

\author{
${\text { Grzegorz Kaczori*, Tomasz Bergel' }{ }^{1} \text {, Piotr Bugajski }{ }^{1} \text {, Jacek Pijanowski }}^{2}$ \\ ${ }^{1}$ Department of Sanitary Engineering and Water Management, University of Agriculture in Cracow, \\ Mickiewicza 24/28, 30-059 Cracow, Poland \\ ${ }^{2}$ Department of Agricultural Land Surveying, Cadaster and Photogrammetry, \\ University of Agriculture in Cracow, Balicka 253a, 30-198 Cracow, Poland
}

Received: 12 May 2014

Accepted: 8 July 2014

\begin{abstract}
Our paper presents an analysis of the factors directly affecting the quantity and quality of sewage discharged from tourist facilities located in national parks and other protected areas regarding natural assets and landscape. The study was based on the results of analyses carried out over one calendar year in the mountain hostel located in Chochołowska Glade in Tatra National Park. The performed analysis revealed that domestic sewage generated in tourist facilities is characterized by high variability, both quantitative and qualitative. These parameters are influenced by: the nature of the object and its location, the load of the facility with tourist traffic and the resulting daily and hourly water consumption. These conditions pose significant problems in the development of efficient sewage treatment technologies. In view of the obtained results, it was concluded that sewage treatment plants, suggested for the use in tourist facilities located in foothill and mountain areas, should be resistant to periodically occurring hydraulic underloading or overloading, as well as to frequent changes in the daily and hourly concentrations of pollutants. They should also be insensitive to frequent and sudden changes in weather conditions, mainly temperature. This type of sewage treatment plant included the solutions based on soil-plant systems or sand filters, as well as the ones located in thermally insulated buildings - sequential biological reactors and flow reactors with biological membrane module.
\end{abstract}

Keywords: protected areas, tourist facilities, domestic sewage

\section{Introduction}

Due to the natural assets and landscape values, domestic sewage generated by tourist facilities situated in protected areas, which in Poland are among others the national park areas, is characterized by a considerable quantitative and qualitative variability. The features are affected by the character of a facility and its location, the facility loading with tourist traffic and the resultant daily and hourly characteristics of water consumption.

*e-mail: rmkaczor@cyf-kr.edu.pl
These conditions pose serious problems for the development of an efficient sewage disposal technology. Moreover, one should also bear in mind the fact that treated sewage is usually discharged into flowing waters classified at purity class I, which may lead to a worsening of these watercourses' purity status [1].

Sewage treatment plants operating by mountain hostels are additionally exposed to the effect of low atmospheric air temperatures, which negatively influence the effectiveness of biogenic compound removal in biological processes occurring in sequential bioreactors and in biofilters [2]. 
Numerous sewage treatment plants operated by mountain hostels in Poland were constructed in the 1960s and '70s. They often require modernization, both due to the outdated or ineffective technology applied and because of the technical state of the installations and equipment. In many objects, sewage is not subjected to treatment, but only periodically stored in holding tanks.

Modernization of sewage treatment plants operated by the mountain hostels at Chochołowska Glade, Gąsienicowa Glade, in the Valley of Five Polish Lakes, and at Markowe Szczawiny under Babia Góra Mt. was conducted within the project "Brand product of mountain tourism; green hostels in the Beskidy-Gorce-Pieniny Range" that was co-financed by the European Union in the framework of the Małopolskie Regional Operational Program 2007-2013. Also, three new sewage treatment plants were constructed on Leskowiec and Stare Wierchy, and by the shepherds' hut over Wierchomla. So far existing outdated sewage disposal systems have been replaced by treatment plants based on BIOVAC SBR technology. Investment enterprises were supported by the Ecofund foundation and the National Environmental Protection Fund.

Despite an apparent improvement of the sewage disposal status in the most popular mountain hostels in southern Poland, still in many cases, construction works and modernization of such facilities will be continued. Results of research on characteristics of water consumption or the quantity and quality of sewage generated by the facilities situated in the protected areas are rarely published in scientific literature, mainly due to the arduousness of such stud- ies resulting from very difficult or sometimes impossible access to such facilities for sample collection. Also, appropriate access permission to such facilities and installation of measuring apparatus is necessary.

In 2011 researchers from the Department of Sanitary Engineering and Water Management and the Department of Agricultural Land Surveying, Cadaster and Photogrammetry of the University of Agriculture in Kraków conducted detailed research on water consumption and the quality of sewage discharged by the mountain hostel on Chochołowska Glade. This publication presents results of that research, which may be utilized for ideas of modernization or design conception of new sewage treatment plants for tourist facilities situated in the protected areas.

The aim of our research was analysis of factors directly affecting the quantity and quality of sewage discharged from tourist facilities situated in national parks and other protected areas regarding the natural or landscape assets.

The analysis covered:

- The amount and irregularity of water consumption

- The number of persons visiting and sleeping at the hostel during a year, in months and weekdays

- The quality of domestic sewage discharged from the hostel, characterized by $\mathrm{BOD}_{5}, \mathrm{COD}$, total suspended solids, total nitrogen, total phosphorus, and $\mathrm{pH}$

\section{Characteristics of the Analyzed Facility}

The object of research was a mountain hostel situated in Chochołowska Glade, in a protected area of Tatra National Park (Fig. 1).

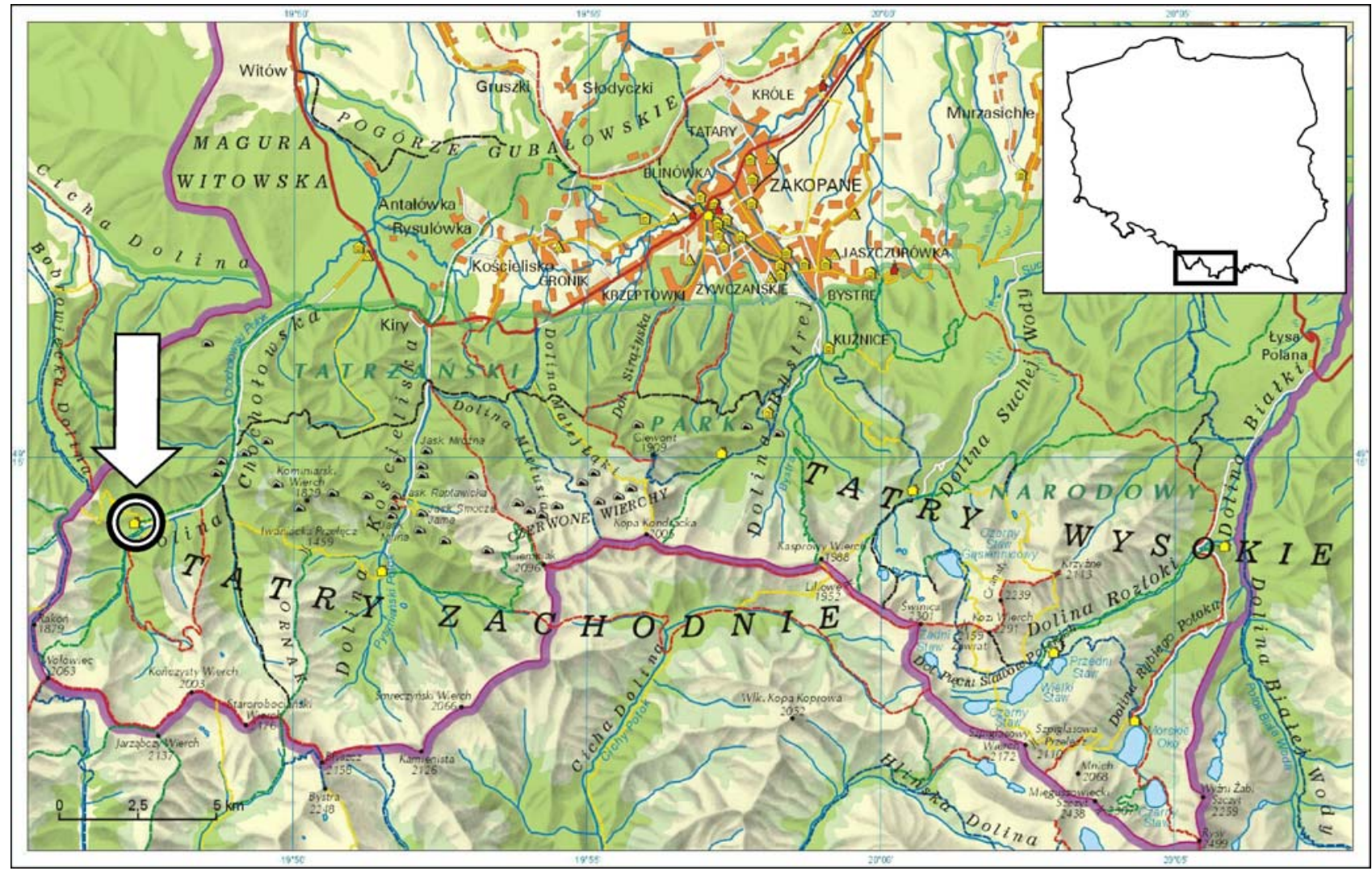

Fig. 1. Location of the studied object in Poland and the Western Tatras. 
The glade and hostel are among the most frequently visited places in the Polish part of the Tatras. In recent years the number of tourists visiting this place has increased considerably. On the basis of entrance tickets to Chochołowska Glade sold in 2008-2010, the average number of visitors per year is 157,800 . In its present shape the hostel was commissioned in 1953. The facility was built at an altitude of $1,148 \mathrm{~m}$ a.s.l. and is the largest mountain hostel in the Polish part of the Tatras.

The hostel has 133 sleeping places. In the summer season it offers seating capacity for consumption for 160 persons and in the winter season for 100 people. Permanent personnel of the hostel numbers 12. The hostel is supplied with potable water and water for domestic use from the surface water intake on Bobrowiecki Stream. Water is stored in two underground containers of reinforced concrete and supplied to the building by a gravity-fed system. 134 sanitary facilities installed in the building are potential sewage discharge points. Among these the most numerous are wash basins (67), toilet bowls (32), and shower tubs (14). The other 14 fittings are: kitchen sinks, bathtubs, urinals, bidets, and washing machines. The needs of tourists using the accommodation at the hostel are met mainly by bathrooms located in the corridors on each floor of the building. Most of the rooms have wash basins. Tourists using the hostel during the day have access to toilets located on the lowest floor beside the main entrance.

\section{Methods}

During investigations we determined the number of tourists using the hostel, water consumption, and quality of sewage discharged from the hostel from 01.01.2011 to 31.12.2011. Daily volume of consumed water was established on the basis of the indications of the main water meter Powogaz MW65, checked daily at 08.00. The number of persons staying overnight at the hostel was obtained from the guest register at the reception desk. The number of people visiting the hostel was registered constantly using a Nice BF photocell coupled with Mini-Log B impulse recorder manufactured by Endress + Hauser. At low and high hostel loading with tourist traffic, sewage samples were collected in the catch pit on the house drain by which sewage is gravitationally conveyed to the operating sewage treatment plant. Over the period of investigation the samples were collected 10 times - samples of sewage from daytime hours whereas on a select day sewage was sampled at hourly intervals (from 07:00 to 24:00). The sewage composition was determined at the Laboratory of Water and Sewage Quality Assessment at the Department of Sanitary Engineering and Water Management, University of Agriculture in Kraków. Sewage quality was analyzed regarding the following indices: $\mathrm{BOD}_{5}$, $\mathrm{COD}$, total suspended solids, total nitrogen, total phosphorus, and $\mathrm{pH}$. Sewage composition was determined by referential methods stated by Polish standards.

\section{Results and Analysis}

At the first stage of the research analyzed was the loading of the mountain hostel on the Chochołowska Glade with tourist traffic in the individual months of the year. The computations were based on the data for 2009-2011, supplied by the hostel manager. On the basis of these data, average monthly number of accommodations provided by the hostel in the analyzed multiannual period was computed. Obtained numerical values were presented as a percentage in Fig. 2. During a year the greatest number of tourists visited the analyzed hostel in August (25.6\% of the annual visitors number). During the period from April to September the hostel was visited by a total of $85.6 \%$ of the annual visitors. From October to March, the hostel was visited on average by only $2.4 \%$ of the annual number of tourists. Even the initial data point to a high irregularity of the hostel loading with tourist traffic, which undoubtedly considerably affected the variability of water consumption and therefore the amount of discharged sewage.

The investigations also analyzed the hourly distribution of the hostel visits by tourists during winter and summer holidays (Fig. 3). The research demonstrated that the number of tourists visiting the hostel reached its peak between 13:00 and 14:00 hrs, both during the winter school break (25\% of the daily tourist number) and summer holidays (16.3\% of the daily tourist number). Between 19:00 and 09:00 the next morning, the number of persons visiting the hostel did not exceed $2 \%$ of the daily number.

One of the most important aspects of sewage disposal is the structure of water consumption, since it determines the volume of sewage supply to the treatment plant [3]. The volume of water consumption in the analyzed hostel consisted of: water collection by personnel for domestic use and preparation of meals, water use by tourists in the daytime. and water collection by tourists accommodated at the hostel. Therefore, the whole volume of water collected in the hostel after use actually changed into sewage and found its way to the treatment plant.

The irregularity of water collection is also important. Fig. 4 presents the range of fluctuations of average daily water consumption on respective days of the week. The analyses were conducted from 1 July to 30 September, i.e. during the period of the most intensive tourist traffic on Chochołowska Glade. Obtained results show that on Saturdays the average value of mean daily water consump-

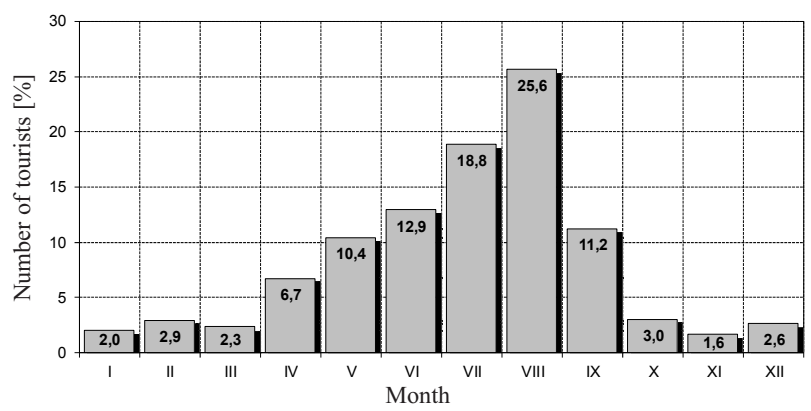

Fig. 2. Monthly load of the mountain hostel with tourist traffic in 2009-2011. 


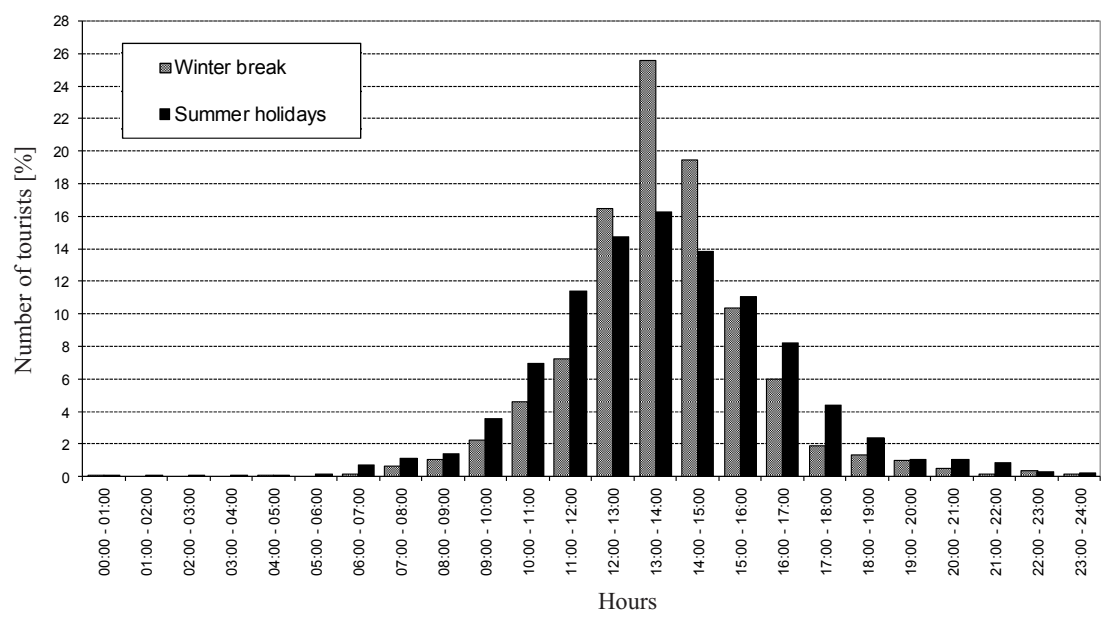

Fig. 3. Distribution of the mean hourly load of the mountain hostel with tourist traffic at select periods of the year.

tion increased by $12.1 \%$ and on Tuesdays by $6.2 \%$, but on Fridays it decreased by $7.4 \%$. On the other days of the week standard weekly deviations of water consumption did not exceed $1.2 \%$. Obtained results indicate that weekly seasonality did not have any significant influence on the fluctuations of daily water consumption and therefore on the daily amount of generated sewage. The value of daily maximum/minimum demand ratio $\mathrm{N}_{\mathrm{d}}$ established on the basis of the analyses was 1.6.

Fig. 5 presents hourly characteristics of water consumption in the analyzed hostel as a percent of mean daily water consumption during the holiday season. The characteristics of water consumption point to a clear increase in water use from 07:00 to 22:00 in relation to the other hourly periods. At this time, hourly water consumption, which was on average $5.3 \%$, fluctuated from 4.7 to $7.1 \%$ of daily consumption.

In the small hours (from 03:00 to 06:00 a.m.), hourly water consumption did not exceed $0.8 \%$, while in the other hours it remained on the level from 1.2 to $3.7 \%$ of average daily consumption. Maximum hourly water consumption registered in the analyzed hostel was $3.3 \mathrm{~m}^{3} \cdot \mathrm{h}^{-1}$ (between 09:00 and 10:00 a.m.). The value of hourly maximum/minimum demand ratio $\mathrm{N}_{\mathrm{h}}$ established on the basis of the investigations was 1.7 .

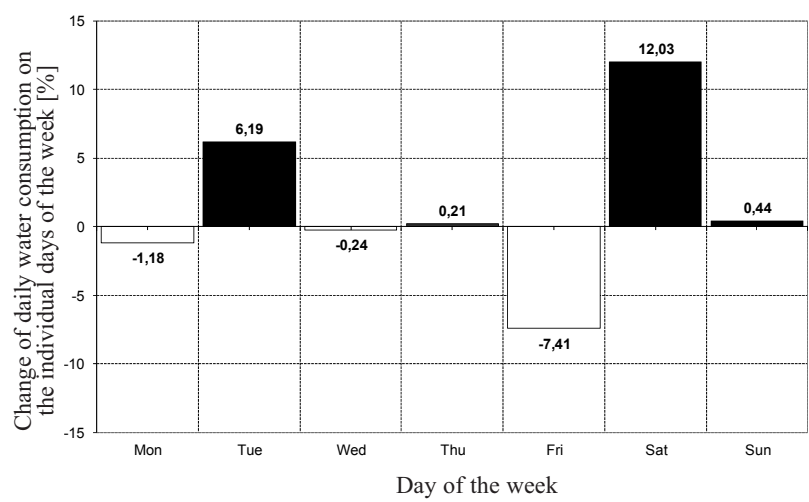

Fig. 4. The effect of weekly seasonality on the percentage changes in average daily water consumption in the mountain hostel during the summer holiday season.
Mean unit water consumption by tourists over the whole period of investigations and during two characteristic periods of the year, when the hostel is visited by the largest number of tourists, was compiled in Table 1. Mean unit water consumption per 1 tourist $(\mathrm{T})$ determined on the basis of the research was $53.3 \mathrm{dm}^{3} \cdot \mathrm{d}^{-1}$, with standard deviation $15.5 \mathrm{dm}^{3} \cdot \mathrm{d}^{-1}$ during the holiday season and $61.4 \mathrm{dm}^{3} \cdot \mathrm{d}^{-1}$ with standard deviation $18.6 \mathrm{dm}^{3} \cdot \mathrm{d}^{-1}$ during the winter school break. Mean unit water consumption for the whole analyzed period of research was $56.0 \mathrm{dm}^{3} \cdot \mathrm{T}^{-1} \cdot \mathrm{d}^{-1}$ with standard deviation $16.8 \mathrm{dm}^{3} \cdot \mathrm{T}^{-1} \cdot \mathrm{d}^{-1}$.

However, it should be pointed out that in some seasons of the year, mainly in the two last weeks of October and in the first two weeks of December, the hostel was not visited by tourists and only its permanent personnel remained in it. Over this period water consumption declined to $9 \mathrm{~m}^{3} \cdot \mathrm{d}^{-1}$, which indicates that at that time hydraulic loading of the treatment plant was lower by $75 \%$ in comparison with the summer holiday season, when average daily water consumption was $35.3 \mathrm{~m}^{3} \cdot \mathrm{d}^{-1}$. Registered maximum daily water consumption in the hostel was $58 \mathrm{~m}^{3} \cdot \mathrm{d}^{-1}$. A detailed analysis of water consumption may be useful for forecasting hydraulic loading of the sewage treatment plant, and therefore for establishing its throughput.

Modernization or design of a sewage disposal system requires additional knowledge about sewage composition. Analyses of sewage discharged by the mountain hostel on Chochołowska Glade revealed that its quality was changing hourly and daily. Table 2 presents compiled characteristic values of six select pollution indices established on the basis of analyses of sewage samples collected during the period of intensified tourist traffic (from 01.07.2011 to 30.09 .2011 ) and in the period of lower tourist traffic (from 28.02.2011 to 20.04.2011).

During the summer holiday season, when the hostel was visited by on average 690 people a day, the quality of sewage discharge by the object was similar to domestic sewage, regarding mean values of $\mathrm{BOD}_{5}, \mathrm{COD}$, and $\mathrm{pH}$ [4]. On the other hand, the sewage was characterized by a higher concentrations of total suspended solids and total nitro- 
Table 1. Unit water consumption in the mountain hostel.

\begin{tabular}{|l|c|c|c|c|}
\hline \multirow{2}{*}{ Unit water consumption } & \multirow{2}{*}{ Unit } & $\begin{array}{c}\text { Summer holidays } \\
\text { from } 01.07 \text { to } 31.08\end{array}$ & $\begin{array}{c}\text { Winter break } \\
\text { from } 17.01 \text { to } 27.02\end{array}$ & Entire investigated period \\
\cline { 1 - 3 } maximum value & \multirow{3}{*}[\mathrm{dm}^{3}\cdot\mathrm{T}^{-1}\cdot\mathrm{d}^{-1}]{} & 86.6 & 97.4 & 97.4 \\
\cline { 1 - 1 } mean value & & 53.3 & 61.4 & 56.0 \\
\cline { 1 - 1 } minimum value & & 27.7 & 34.2 & 27.7 \\
\cline { 3 - 5 } & & &
\end{tabular}

Table 2. Characteristic values of select pollution indices in sewage discharged from the hostel on Chochołowska Glade.

\begin{tabular}{|c|c|c|c|}
\hline \multirow{2}{*}{$\begin{array}{l}\text { Index } \\
\text { [unit] }\end{array}$} & \multirow[b]{2}{*}{ Parameter } & \multicolumn{2}{|c|}{$\begin{array}{l}\text { Parameter value in the } \\
\text { investigated period }\end{array}$} \\
\hline & & $\begin{array}{c}\text { from } \\
01.07 .2011 \text { to } \\
30.09 .2011\end{array}$ & $\begin{array}{c}\text { from } \\
28.022011 \text { to } \\
20.04 .2011\end{array}$ \\
\hline \multirow{3}{*}{$\begin{array}{c}\mathrm{BOD}_{5} \\
{\left[\mathrm{mgO}_{2} \cdot \mathrm{dm}^{-3}\right]}\end{array}$} & maximum & 720.0 & 105.0 \\
\hline & mean & 319.0 & 69.0 \\
\hline & minimum & 299.0 & 24.0 \\
\hline \multirow{3}{*}{$\begin{array}{c}\mathrm{ChZT}_{\mathrm{Cr}} \\
{\left[\mathrm{mgO}_{2} \cdot \mathrm{dm}^{-3}\right]}\end{array}$} & maximum & 1510.8 & 205.5 \\
\hline & mean & 682.1 & 165.2 \\
\hline & minimum & 605.0 & 142.4 \\
\hline \multirow{3}{*}{$\begin{array}{c}\text { Total } \\
\text { suspended } \\
\text { solids } \\
{\left[\mathrm{mg} \cdot \mathrm{dm}^{-3}\right]}\end{array}$} & maximum & 1350.1 & 295.0 \\
\hline & mean & 613.5 & 155.0 \\
\hline & minimum & 575.1 & 34.0 \\
\hline \multirow{3}{*}{$\begin{array}{l}\text { Total nitrogen } \\
{\left[\mathrm{mgN} \cdot \mathrm{dm}^{-3}\right]}\end{array}$} & maximum & 203.1 & 23.9 \\
\hline & mean & 155.8 & 21.2 \\
\hline & minimum & 33.5 & 18.1 \\
\hline \multirow{3}{*}{$\begin{array}{c}\text { Total } \\
\text { phosphorus } \\
{\left[\mathrm{mgP} \cdot \mathrm{dm}^{-3}\right]}\end{array}$} & maximum & 22.2 & 13.3 \\
\hline & mean & 13.3 & 6.9 \\
\hline & minimum & 2.5 & 2.2 \\
\hline \multirow{3}{*}{$\mathrm{pH}$} & maximum & 8.0 & 7.8 \\
\hline & mean & 6.9 & 6.7 \\
\hline & minimum & 5.7 & 6.2 \\
\hline
\end{tabular}

gen than encountered in typical domestic sewage, and lower content of total phosphorus. This is connected with the structure of water consumption showing definitely its highest use in toilets and bathrooms.

Quite different results were obtained for the samples of sewage collected outside the period of summer holidays and winter break. Sewage was greatly diluted. Mean $\mathrm{BOD}_{5}$ value outside the holiday season was c.a. $78 \%$ lower, COD by $76 \%$, total suspended solids by $75 \%$, total nitrogen by $86 \%$, and total phosphorus by $48 \%$ lower in comparison with the holiday season. Mean value of $\mathrm{pH}$ in both analyzed periods was on a similar level from 6.7 to 6.9. It should be pointed out that during the same period also almost $50 \%$ lower daily water consumption was observed. Therefore, it may be assumed that outside the period of intensified tourist traffic sewage would contain very low loads of organic carbon compounds, which may affect negatively the activity of activated sludge in the treatment plants based on biological reactors.

Inappropriate index ratios also occurred outside the holiday season: $\mathrm{COD}: \mathrm{BOD}_{5}$ (noted value was 2.4 whereas the required one should be lower than or equal to 2.2), $\mathrm{BOD}_{5}: \mathrm{N}_{\mathrm{og}}$ (registered value was 3.3; the required one should be higher than or equal to 4 ), and $\mathrm{BOD}_{5}: \mathrm{P}_{\text {og }}$ (noted value was 10.0 whereas the required one should be higher than or equal to 25). These values indicate a low content of biodegradable substances in sewage, so problems should be expected in biological phosphorus removal and denitrification processes, whose aim is to diminish biogenic compound content in sewage supplied to the receiving water.

Designing a sewage treatment plant also requires knowledge about the size of unit loads of pollutants in raw sewage. In the case of our analyzed mountain hostel, unit loads of individual pollutants per tourist were as follows: for $\mathrm{BOD}_{5}-16.3 \mathrm{~g} \cdot \mathrm{d}^{-1}, \mathrm{COD}-34.8 \mathrm{~g} \cdot \mathrm{d}^{-1}$, total suspended solids $-31.3 \mathrm{~g} \cdot \mathrm{d}^{-1}$, total nitrogen $-8.0 \mathrm{~g} \cdot \mathrm{d}^{-1}$, and total phosphorus $-0.7 \mathrm{~g} \cdot \mathrm{d}^{-1}$. Considering that pollutant concentrations in raw sewage change depending on the number of tourists visiting the hostel whereas this changes depending on the day of the week, Fig. 6 shows mean daily values of $\mathrm{BOD}_{5}$ and COD from Monday to Sunday.

Sewage samples for this analysis were collected during the period of intensive loading of the hostel with tourist traffic. The data presented in Fig. 6 indicate that $\mathrm{BOD}_{5}$ from Monday to Thursday fluctuated from 238 to 322 $\mathrm{mgO}_{2} \cdot \mathrm{dm}^{-3}$, whereas during the period from Friday till Sunday it grew to $491 \mathrm{mgO}_{2} \cdot \mathrm{dm}^{-3}$. A similar relationship was observed for COD. From Monday till Thursday the value of this index fluctuated from 508 to $710 \mathrm{mgO}_{2} \cdot \mathrm{dm}^{-3}$, whereas over the weekend it increased, reaching a maximum of $1,047 \mathrm{mgO}_{2} \cdot \mathrm{dm}^{-3}$ on Sunday.

\section{Discussion of Results Regarding the Choice of Sewage Disposal System for Tourist Facilities}

The research results presented in this paper revealed that domestic sewage discharged from tourist facilities, such as mountain hostels, undergo large quantitative fluctuations. The amount of daily sewage outflow was changing 


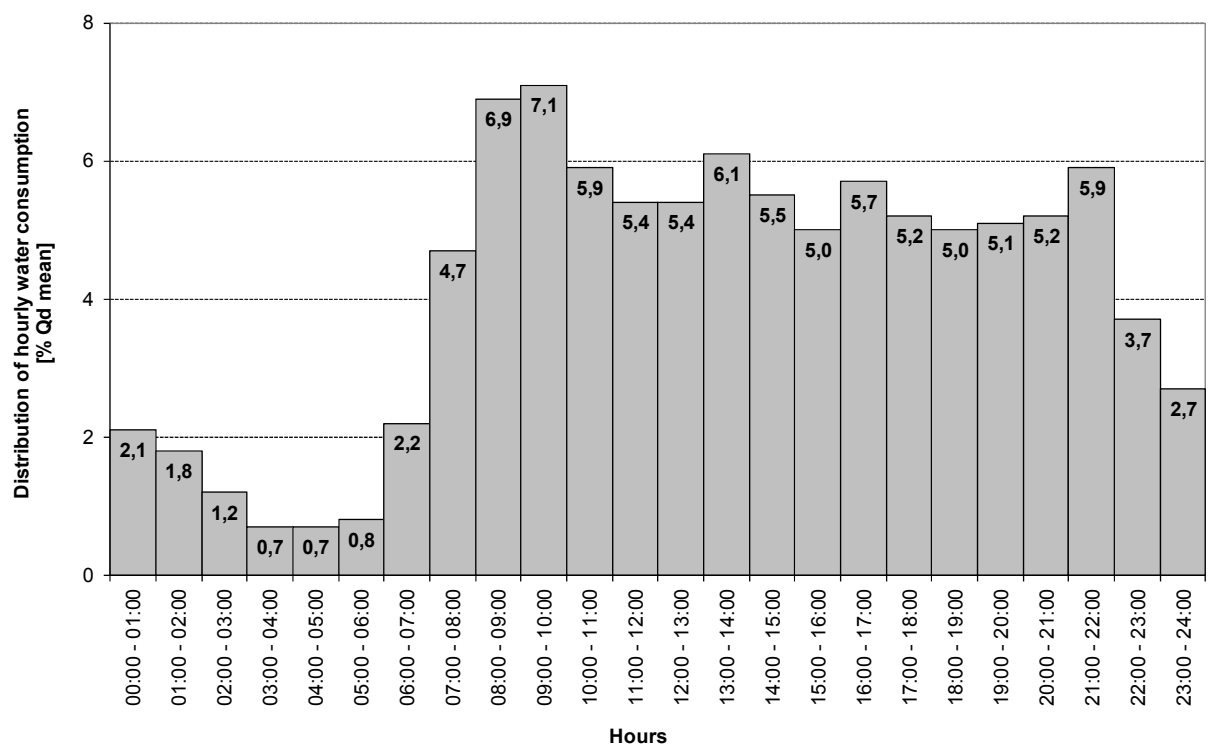

Fig. 5. Distribution of hourly water consumption in the mountain hostel in Chochołowska Glade during the summer holiday season.

within the range from 9.0 to $58.5 \mathrm{~m}^{3} \cdot \mathrm{d}^{-1}$. Therefore, in comparison with the summer holiday or winter school break periods, hydraulic loading of the treatment plant may decrease over six-fold at times of very low tourist traffic. Świerczok et al. [5] obtained similar results concerning a high daily variability of sewage outflow from "Samotnia" mountain hostel in Karpacz. They registered fluctuations of daily water consumption within the range from 1.2 to 15.1 $\mathrm{m}^{3} \cdot \mathrm{d}^{-1}$. A considerable variability of pollutant concentrations was observed in the sewage discharged by the hostel on Chochołowska Glade on individual days during the year. For instance, $\mathrm{BOD}_{5}$ was changing within the range from 24 to $720 \mathrm{mgO}_{2} \cdot \mathrm{dm}^{-3}$, COD from 142 to $1511 \mathrm{mgO}_{2} \cdot \mathrm{dm}^{-3}$, total suspended solids from 34 to $1350 \mathrm{mg} \cdot \mathrm{dm}^{-3}$, total nitrogen from 18 to $203 \mathrm{mg} \mathrm{N} \cdot \mathrm{dm}^{-3}$, total phosphorus from 2 to 22 $\mathrm{mgP} \cdot \mathrm{dm}^{-3}$, and $\mathrm{pH}$ from 6.2 to 8.0. The authors of the above-mentioned publication [5] obtained similar results concerning variability of respective pollutant index values in sewage outflowing from the Samotnia mountain hostel in Karpacz.

Keeping in mind research results presented in this paper, some suggestions may be made regarding the method of pollutant disposal in sewage discharged from

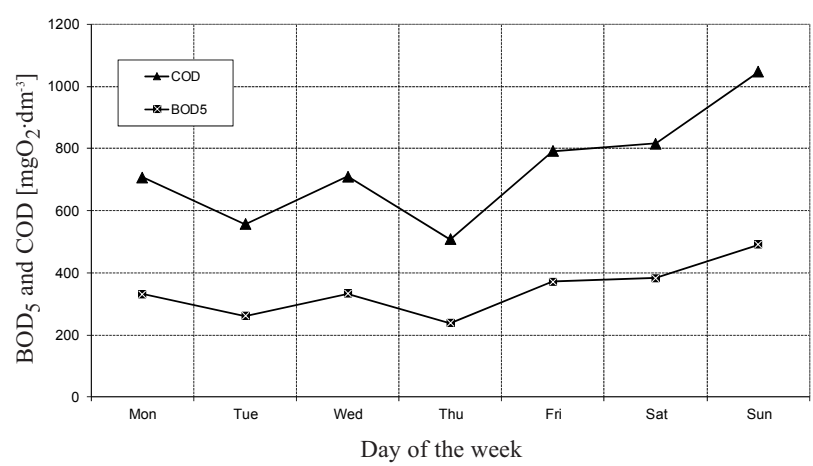

Fig. 6. Mean daily values of $\mathrm{BOD}_{5}$ and $\mathrm{COD}$ in raw sewage outflowing from the hostel each day of the week. tourist facilities, such as hostels, situated in sub-mountainous and mountainous areas. Sewage treatment plants operating there should be resistant to seasonal hydraulic underloading or overloading and frequent changes of daily and hourly pollutant concentrations. They should also be insensitive to frequent and rapid changes of atmospheric factors, mainly air temperature.

Representative sewage disposal systems meeting the formal requirements were suggested in their papers among others by Jucherski [6, 7], Jóźwiakowski [8], Gajewska, and Obarska-Pempkowiak [9]. These are mainly sewage treatment plants based on soil-vegetation systems. They use natural purification processes that occur in wetland ecosystems. Sewage plants of this type are integrated into the landscape and because of the subsurface sewage flow may successfully function effectively also under conditions of seasonally lower air temperatures. A connection in series of vertical and horizontal sewage flow, usually combined with Bioclere $^{\circledR}$ biological beds [10] or LECA beds (with keramzyte filling) [11] produce very good results for pollutant removal.

Another solution may be sand filters with vertical flow, which are recommended for cleaning both small and large amounts of sewage, e.g. from public utility or service providing facilities. The principle of sand filters operation relies on seasonal sewage discharge to filter beds usually built of sand, where solid, colloidal or dissolved pollutants are removed from the sewage in physical, chemical, and biological processes. Microorganisms developing in the bed and decomposing organic substances also play a crucial role in sewage cleaning [12]. Application of this solution guarantees obtaining purified sewage of high quality, reducing environment pollution. However, the main drawbacks of sand filters and soil-vegetation treatment plants is usually the large area required for the investment and the necessity to place some of the plant elements under the surface, which may pose a serious problem, especially in the mountains. 
An alternative solution for a mountain hostel may be a small sewage treatment plant with an open flow bioreactor. However, such an object should be located in a building with thermal insulation to prevent the unfavorable effect of low atmospheric air temperatures. Temperature is the key factor influencing the effectiveness of biogenic compound removal in activated sludge chambers. Because of potential hydraulic overloading of the object, its seems justified to apply a membrane module in the bioreactor (MBR). This solution allows for potential excluding from the technological process of a secondary settling tank from which a sludge containing phosphorus compounds or nitrates may be washed out at maximum flows. Moreover, in the process of micro or nano-filtration the membrane module allows us to obtain a better quality of purified sewage practically free of suspension, bacteria, and viruses. In MBR reactors, a higher concentration of activated sludge is obtained in the reactor, which affects better results of pollutant removal.

Another recommended solution may be the application of sewage treatment plants using hybrid systems, i.e. a combination of activated sludge technology and biological beds with suspended or attached biomass. They reveal a better resistance to quantitative and qualitative changes of sewage than the traditional activated sludge and are free of some drawbacks of biological beds. They also allow for simultaneous removal of nitrogen and phosphorus compounds from the sewage [13].

The outdated sewage disposal systems so far functioning in the mountain hostels situated in the Valley of Five Polish Lakes and at Murowaniec Hostel in Gąsienicowa Glade were replaced by treatment plants based on BIO$\mathrm{VAC}^{\circledR}$ SBR technology. The treatment plants of this type are based on sequencing batch reactors working in a double or multiple system [14]. Modular construction combines in the parallel system two or more activated sludge tanks, resulting in high resistance of the object to hydraulic overloading or underloading. According to the manufacturer, a BIOVAC sewage treatment plant may function correctly even at the minimum sewage inflow constituting $15 \%$ of nominal throughput. Hermetically sealed tanks (eliminated odor nuisance for the environment) placed in the thermally secured containers are invulnerable to low ambient temperatures. The results of this type of treatment plant efficiency, published so far [14], give hope that at their proper and sensible operation many environmentally precious and water-head sections of watercourses located in the immediate vicinity of mountain hostels will be protected against pollution from the untreated sewage.

In summary it should be stated that supporting the realization of such projects as "Brand product of mountain tourism; green mountain hostels in the Beskidy-GorcePieniny Range" and other endeavors of this type, should be in the interest of all who care about protection of the natural environment, particularly valuable habitats and landscapes of the sub-mountainous and mountainous areas of southern Poland. This paper presented unique results of research which may be used for the development of a modernization concept or design of new sewage treatment plants for tourist facilities situated in the protected areas.

\section{Conclusions}

The following conclusions have been formulated on the basis of comprehensive research conducted in 2011 at the mountain hostel situated on Chochołowska Glade:

1. Municipal sewage discharged from tourist facilities (such as mountain shelters) undergo very strong quantitative fluctuations. Their daily volume may increase even 6-fold in comparison with the lowest observed sewage outflow.

2. On the basis of water consumption analysis in the investigated facility, it was established that while designing a sewage treatment plant for mountain shelters, one should assume a unit sewage outflow of $56.0 \mathrm{dm}^{3} \cdot \mathrm{d}^{-3}$ per 1 tourist, with standard deviation $16.8 \mathrm{dm}^{3} \cdot \mathrm{d}^{-3}$ at coefficients values $\mathrm{N}_{d}=1.6$ and $\mathrm{N}_{\mathrm{h}}=1.7$.

3. Sewage outflow from the mountain hostel reveals a large variability of pollutant concentrations. $\mathrm{BOD}_{5}$ was changing within the range from 24 to $720 \mathrm{mgO}_{2} \cdot \mathrm{dm}^{-3}$, COD from 142 to $1,511 \mathrm{mgO}_{2} \cdot \mathrm{dm}^{-3}$, total suspended solids from 34 to $1,350 \mathrm{mg} \cdot \mathrm{dm}^{-3}$, total nitrogen from 18 to $203 \mathrm{mg}$ $\mathrm{N} \cdot \mathrm{dm}^{-3}$, and total phosphorus from 2 to $22 \mathrm{mg} \mathrm{P} \cdot \mathrm{dm}^{-3}$.

4. While designing a sewage treatment plant for a mountain shelter, one may apply the following unit values (per 1 tourist) of pollutant loads, determined on the basis of research: $\mathrm{BOD}_{5}-16 \mathrm{~g} \cdot \mathrm{d}^{-1}, \mathrm{COD}-35 \mathrm{~g} \cdot \mathrm{d}^{-1}$, total suspended solids $-31 \mathrm{~g} \cdot \mathrm{d}^{-1}$, total nitrogen $8 \mathrm{~g} \cdot \mathrm{d}^{-1}$, and total phosphorus $0.7 \mathrm{~g} \cdot \mathrm{d}^{-1}$.

5. Analysis of sewage outflowing from the mountain hostel revealed that it was characterized by a low concentration of biodegradable substances, which may pose problems for the biological processes of dephosphatation and denitrification.

6. The selection of a sewage disposal system for tourist facilities situated in the protected areas should be based in the first place on solutions using soil-vegetation beds or sand filters. Apart from their high operational efficiency, these facilities integrate very well with the natural landscape. The use of sewage treatment plants based on activated sludge technology (mainly with modular sequencing flow bioreactors with ultrafiltration membrane or hybrids of activated sludge and biological beds) is also possible. However, these objects should be placed in a thermally insulated building due to the unfavorable effect of low atmospheric air temperatures on biological processes.

\section{References}

1. KASPRZYK B., KISIELOWSKA E. Quality of surface and underground waters in the Lejova Valley in the Tatra Mts. Gaz, Woda i Technika Sanitarna, 6, 224, 2011 [In Polish].

2. KACZOR G., BUGAJSKI P. Impact of snowmelt inflow on temperature of sewage discharged to treatment plants. Pol. J. Environ. Stud., 21, (2), 381, 2012.

3. BERGEL T., KACZOR G. The volume of wastewater discharged from rural households to the sewer system in the light of tap water consumption structure. Pol. J. Environ. Stud., 16, (2A), part II, 109, 2007. 
4. KACZOR G. Pollutant concentrations in sewage discharged from rural sewer systems of the Malopolskie voivodeship. Infrastruktura i Ekologia Terenów Wiejskich, 9, 97, 2009 [In Polish].

5. ŚWIERCZOK R., ŁUKAWSKA E., WŁODYGA J. Sewage treatment on an example of "Samotnia" mountain hostel in Karpacz. Ochrona Środowiska, 1, (56), 41, 1995 [In Polish].

6. JUCHERSKI A. Efficiency of domestic sewage treatment in soil biotechnology and soil-vegetation treatment plants in mountain areas. Zeszyty Naukowe AR w Krakowie, 365, 371, 2000 [In Polish].

7. JUCHERSKI A. Quasi-technical sewage treatment plants with soil-vegetation filtering beds in individual sanitary sewage treatment in the valuable natural habitats in the Carpathians. In: Monography, Ed. J. Rak: Selected aspects of water protection and water management in the SouthEastern Poland. Eastern Slovakia and Western Ukraine. Wydawnictwo Muzeum Regionalnego w Brzozowie, pp. 167-183, 2012 [In Polish].

8. JÓŹWIAKOWSKI K. The experience from twelve-year operation of reed bed treatment system with vertical flow. Pol. J. Environ. Stud., 16, (2A), part III, 516, 2007.
9. GAJEWSKA A., OBARSKA-PEMPKOWIAK H. 20 years of experience of hybrid constructed wetlands exploitation in Poland. Rocznik Ochrony Środowiska, 11, 876, 2009 [In Polish].

10. GAJEWSKA M., KOPEĆ Ł., OBARSKA-PEMPKOWIAK H. Operation of small wastewater treatment facilities in scattered settlement. Rocznik Ochrony Środowiska, 13, 207, 2011.

11. JUCHERSKI A., NASTAWNY M. Effectiveness of removing nitrogen compounds from domestic sewage in trickling LECA beds of different hydraulic and organic substrate loads. Problemy Inżynierii Rolniczej, 4, (78), 171, 2012 [In Polish].

12. CHMIELOWSKI K. Defining the optimal range of a filter bed's d10 replacement diameter in vertical flow sand filters. Environment Protection Engineering, 3, 35, 2008.

13. WAŁĘGA A., MIERNIK W., KOZIEŃ T. The efficiency of a domestic sewage treatment plant type RetroFAST. Przemysł Chemiczny, 5, 610, 2008 [In Polish].

14. MARZEC M., JÓŹWIAKOWSKI K., GIZIŃSKA M., PYTKA A. Problems of operation and effects of pollution removal in wastewater treatment plants such as BIOVAC. Gaz, Woda i Technika Sanitarna, 2, 85, 2012 [In Polish]. 